\title{
Antioxidant activity and phytochemical screening of different solvent extracts Cluasena excavate burm F. (Rutaceae)
}

\begin{abstract}
The aim of this study was to screen different solvent extracts of Cluasena excavata (leaves) to display potent antioxidant activity and also the total phenolic and flavonoid contents in order to find possible sources for future novel antioxidants in food and pharmaceutical formulations. Measurement of free radical scavenging activity (RSA) [reactions with 1,1-diphenyl- 2-picrylhydrazyl radical (DPPH), Nitric oxide scavenging assay by using UV-double beam spectrometer. Among the different extracts tested, the methanol extract showed significant antioxidant activity. Medicinal plants are widely spread in Tamil Nadu and their biological and phytochemical properties are not thoroughly evaluated. In this present study, crude extract of Cluasenaexcavation (leaves) were screened to regulate their active chemical constituents using conventional chemical tests (precipitation and color reagents) and antioxidant activities were determined using the DPPH radical scavenging method. The phytochemical tested shows the presence of various secondary metabolites such as alkaloids, flavonoids, glycosides, phenols, Terpenoids, saponins, and tannins etc. The plants revealed promising antioxidant activity, and require further studies to throw light on their chemical composition and antioxidant properties.
\end{abstract}

Volume I Issue I - 2016

\author{
Elumalai K, Kasinathan ID \\ Department of Advanced Zoology \& Biotechnology, Govt Arts \\ College (Autonomous), India
}

Correspondence: Elumalai Kuppusamy, Department of Advanced Zoology \& Biotechnology, Govt Arts College (Autonomous), Nandanam, Chennai -600 035, Tamilnadu, India, Email mailtokasi@gmail.com

Received:September I, 2016 | Published: September 29, 2016

Keywords: clausena excavate, DPPH; FRAP, NO2, UV absorption, ROS

\section{Introduction}

Now-a-days, there is an increased occurrence of various diseases like cardiovascular disease, neurological disorders, cancer, diabetes and autoimmune disease due to the presence of free radicals. Bandyopadhyay et al. ${ }^{1}$ Antioxidant is defined as the agent that neutralizes the effect produced by free radical Fang Y et al. ${ }^{2}$ The antioxidant can be classified into two categories, namely enzymatic and non-enzymatic. The enzymatic antioxidants are produced itself in our body, whereas most of non-enzymatic antioxidants are obtained from either natural plants or synthetics which are used for the treatment for various diseases Lee $\mathrm{J}$ et al. $^{3}$ and Cuzzocrea $\mathrm{S}$ et al. ${ }^{4}$ A number of side effects like liver damage and mutagenesis are associated with the use of antioxidants obtained from synthetic sources Grice HC. ${ }^{5}$ Thus, researchers are exploring natural resources to find out newer and safer natural antioxidants. The potentially reactive derivatives of oxygen, attributed as reactive species (ROS), are continuously generated inside the human body. The generated ROS are detoxified by the antioxidants present in the body. However, overproduction of ROS and/or inadequate antioxidant defense can easily affect and persuade oxidative damage to various bimolecular, including proteins, lipids, Natural antioxidants lipoproteins and DNA. The WHO estimates that up to $80 \%$ of people still rely mainly on traditional remedies such as herbs for their medicine. ${ }^{6}$ India has been identified as a major resourceful area in the traditional and alternative medicines globally. Multi-factorial health beneficial activity of these plant extracts has been attributed to multi-potent anti-oxidant, antimicrobial, anti-cancer, anti-ulcerative and anti-diabetic properties. Several medicinal plants (Rasayana) have also been extensively used in the Indian traditional (Ayurveda) system of medicine for the treatment of number of diseases. Some of these plants have shown potent antioxidant activity. Kaur $\mathrm{C}$ et al. ${ }^{7}$ and Aqil et al. ${ }^{8}$ The WHO estimates that up to $80 \%$ of people still rely mainly on traditional remedies such as herbs for their medicine Tripathi et al. ${ }^{6}$

Currently, the search for plant sources of antioxidants is gaining momentum with Clausena excavata (Rutaceae family) among the plants targeted. C. excavata is a medicinal plant widely distributed in Southeast Asia and is known by unique local names, such as Chamat in Thailand and Jia huang pi in China. In Malaysia the plant is locally known as "Cherek hitam" and "Kemantu hitam. In Tamil Kattukaruveppilai or Kattu veppilai. "The leaves of the plant are used in folklore medicine for the treatment of several illnesses such as malaria, headache, abdominal pain, dysentery, pulmonary tuberculosis, diarrhea, cold, wound, snakebite, and poisoning. Recent studies showed that the plant also possessed immune-modulator Manosroi et al., ${ }^{9}$ analgesic Rahman et al. ${ }^{10}$ anti- inflammatory, antivirus, anticancer, ${ }^{11}$ antioxidant Guntupalli et al. ${ }^{12}$ antimycobacterial Sunthitikawinsakul et al., ${ }^{13}$ and antifunga ${ }^{14}$ activities. C. excavata has been reported to exhibit one of the highest beneficial biological activities among Clausenagenus Arbab et al. ${ }^{15}$

\section{Material and methods}

\section{Source of plant materials}

Leaves of Clausena excavata, were collected from Yercaud hills, Salem District, Tamilnadu, India. The collected plant specimen was identified by Taxonomist from the Department of Botany, Govt. Arts College (Autonomous), Chennai-600035, Tamil Nadu, India and The Voucher specimen was deposited in the laboratory. 


\section{Preparation of plant extracts}

The dried leaves $(100 \mathrm{~g})$ were powdered mechanically using commercial electrical stainless steel blender and extracted sequentially with hexane, ethyl acetate and methanol $(500 \mathrm{ml}$, Ranchem), in a soxhlet apparatus separately until exhaustion. The extracts were individually concentrated under reduced pressure of $22-26 \mathrm{~mm}$ hg at $45^{\circ} \mathrm{C}$ by 'Rotavapour' (SUPERFIT PBU-6D) and the residue obtained was stored at $4^{\circ} \mathrm{C}$ in an amber vial. Then the vials were named and covered with silver foil and transported to the laboratory. Until use those vials were kept in cool and dark place at $4^{\circ} \mathrm{C}$.

\section{Antioxidant activity - DPPH (2, 2-diphenyl-I- picrylhydrazyl) radical scavenging assay}

The Radical Scavenging Activity (RSA) of different extracts was determined by using DPPH assay following the method of Chang et al. ${ }^{16}$ with small modification. The decrease in the absorption of the DPPH solution at $517 \mathrm{~nm}$ after the addition of antioxidant was measured in a cuvette containing $2.960 \mu \mathrm{l}$ of $0.1 \mathrm{~mm}$ methanolic DPPH solutions; $40 \mu \mathrm{l}$ of 20 to $200 \mu \mathrm{g} / \mathrm{mL}$ of plant extracts after vortexing the mixture thoroughly. The setup was left at dark in room temperature and the absorption was monitored after 20 minutes by using double beam UV spectrophotometer. Ascorbic acid and Butylated hydroxytoluene (BHT) were used as references. The ability of the plant extract to scavenge DPPH radical was calculated by the following equation

$$
\% \operatorname{RSA} \frac{A c-A s}{A c} \times 100
$$

\section{Where $\mathrm{Ac}=\mathrm{Absorbance}$ of control; $\mathrm{As}=\mathrm{Abs}$ rbance of sample}

Abs. control=Absorbance of DPPH radical+ethanol; Abs. sample=absorbance of DPPH radical+plant extract. Measurements were performed in triplicates. Absorbance values were corrected for radicals decay using blank solutions.

\section{Ferric reducing antioxidant power (FRAP) assay}

FRAP reagent $(1.8 \mathrm{ml})$ was mixed with $0.2 \mathrm{ml}$ of test sample, then incubated at $37^{\circ} \mathrm{C}$ for 10 minutes in a water bath. The FRAP reagent contains 20mM TPTZ (2, 4, 6-tri(2-pyridial)-S-triazine) solution $20 \mathrm{mM} \mathrm{FeCl}_{3}, 6 \mathrm{H}_{2} \mathrm{O}$ and $0.3 \mathrm{~m}$ Acetate buffer with $\mathrm{p}^{\mathrm{H}}$ 3.6. After incubation the absorption were measured immediately at $593 \mathrm{~nm}$. The above mixture without the plant extract served as control. Methanolic solution of known Fe (II) concentration was used as standards. The values were expressed as $\mathrm{mmol} \mathrm{Fe}$ (II)/g dry weight of the extract. The assay was carried out in triplicate and the mean values with \pm S.D are presented.

\section{Nitric oxide scavenging assay}

The nitric oxide radical inhibition was estimated by the use of Griess Illosvoy reaction Garrat ${ }^{17}$ for dichloromethane, ethyl acetate and methanol extract of Clausena excavata with positive control and standard. The negative control was also prepared with distilled water and the reagent. The absorption was measured $540 \mathrm{~nm}$ then the $\%$ of inhibition was calculated.

$$
\% \mathrm{NO} 2 \frac{\mathrm{Ac}-\mathrm{As}}{\mathrm{Ac}} \mathrm{X} 100
$$

Where Ac=Absorbance of control; As=Absorbance of sample

\section{Estimation of flavonoids}

The flavonoids content was determined as follows: $0.1 \mathrm{ml}$ of sample method Markham et al. ${ }^{18}(1 \mathrm{mg} / \mathrm{ml})$ was mixed with $2 \mathrm{~g} \mathrm{ml}$ of $10 \%$ aluminum chloride and $0.1 \mathrm{ml}$ of sodium acetate $(1 \mathrm{M})$. To this mixture, $4.3 \mathrm{ml}$ of $80 \%$ methanol was added to make $5 \mathrm{ml}$ volume. This mixture was vortexed and the absorbance was measured spectrophotometrically at $415 \mathrm{~nm}$. The value of optical density was used to calculate the total flavonoid content present in the sample.

\section{Estimation of total phenolic content}

Total phenolic content was estimated using the $0.5 \mathrm{ml}$ Folin-reagent method Harborne et al. ${ }^{19}$ Samples $(100 \mu l)$ were mixed thoroughly with $2 \mathrm{ml}$ of $2 \% \mathrm{Na}_{2} \mathrm{CO}_{3}$. After $1 \mathrm{~min}$. $100 \mu \mathrm{l}$ of Folin-Ciocalteu reagent was added to the mixture. The resulting mixture was allowed to stand at room temperature for $30 \mathrm{~min}$ and the absorbance was measured at $650 \mathrm{~nm}$ against a blank. Total phenolic content was expressed as gram of gallic equivalents per 100 gram of dry weight of the plant samples.

\section{Results}

\section{Antioxidant activity (DPPH assay) assay of hexane, ethyl acetate and methanol extracts of Clausena excavata}

Antioxidant activity with reference to 2,2-diphenyl-1picrylhydrazyl assay of hexane extract of Clausena excavata was tested with concentration ranging from $10-100 \mu \mathrm{g} / \mathrm{ml}$ as shown in Figure 1 . The data pertaining to the activity clearly revealed that the percentage of antioxidant activity was ranged from $49.90 \%$ to $79.90 \%$. Similarly, the antioxidant activity with reference to 2, 2-diphenyl-1picrylhydrazyl assay of ethyl acetate extract of $C$. excavata was tested with concentration ranging from $10-100 \mu \mathrm{g} / \mathrm{ml}$ as shown in Figure 2. The data pertaining to the activity clearly revealed that the percentage of antioxidant activity was ranged from $51.21 \%$ to $82.37 \%$.In the same way, the antioxidant activity of 2,2-diphenyl-1-picrylhydrazyl assay of methanol extract of C. excavata was tested with concentration ranging from $10-100 \mu \mathrm{g} / \mathrm{ml}$ as shown in $\mathrm{F}$. The data pertaining to the activity clearly revealed that the percentage of antioxidant activity was ranged from $56.23 \%$ to $89.23 \%$.

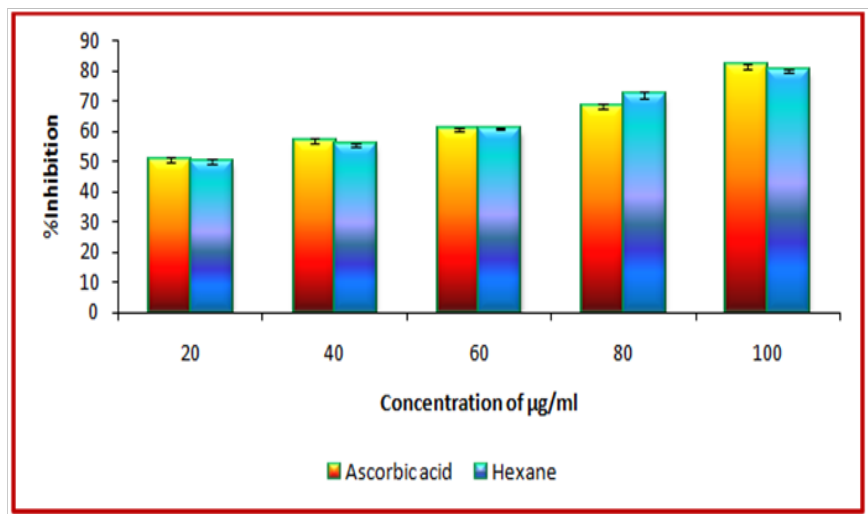

Figure I Antioxidant activity (2, 2-diphenyl-I-picrylhydrazyl Assay) of hexane extract of Clausena excavata leaf. 


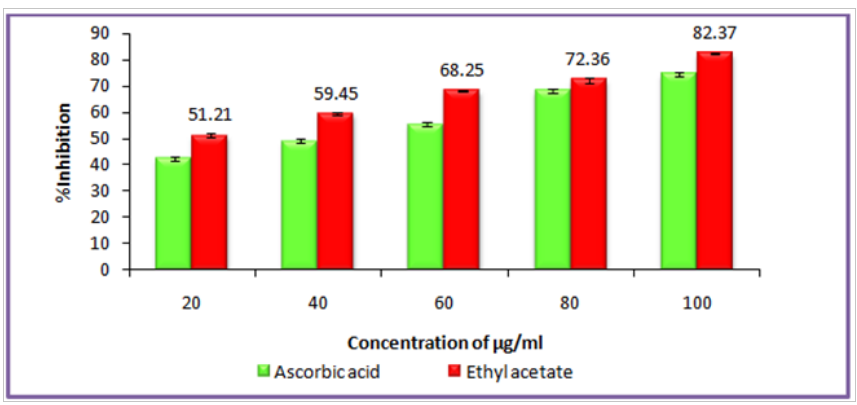

Figure 2 Antioxidant activity (2, 2-diphenyl-I-picrylhydrazyl Assay) of ethyl acetate extract of Clausena excavata leaf

\section{Antioxidant activity (FRAP) of hexane, ethyl acetate and methanol extracts of Clausena excavata}

Antioxidant activity (FRAP) of different solvent extracts of C. excavata was tested and the data observed were depicted in the Table 1. It was observed that the FRAP activity was ranged from 12.42 to $68.22 \%$ hexane extract of $C$. excavata. In the same way, the ethyl acetate extract of $C$. excavata leaf showed 16.22 to 72.12 . Whereas, the maximum antioxidant activity (FRAP) was recorded in the methanol extract and the percentage was ranged from 18.42 to $82.22 \%$ (Table 1) (Figure 4).

Table I: Antioxidant activity (FRAP assay) of different solvent extract of Clausena excavata leaf.

Values represent mean \pm S.D of three replications. FRAP-Ferric Reducing Antioxidant Power

\begin{tabular}{llll}
\hline \multirow{2}{*}{ Concentrations tested } & \multicolumn{3}{l}{ Solvents tested } \\
\cline { 2 - 4 } & Hexane & Ethyl acetate & Methanol \\
\hline 20 & $12.42 \pm 1.16$ & $16.22 \pm 2.00$ & $18.42 \pm 1.62$ \\
40 & $38.12 \pm 2.18$ & $44.38 \pm 2.11$ & $48.36 \pm 1.00$ \\
60 & $44.24 \pm 4.31$ & $54.12 \pm 3.18$ & $62.32 \pm 1.74$ \\
80 & $52.38 \pm 3.00$ & $62.22 \pm 2.02$ & $72.18 \pm 2.84$ \\
100 & $68.22 \pm 3.11$ & $72.12 \pm 2.08$ & $82.22 \pm 3.16$ \\
\hline
\end{tabular}

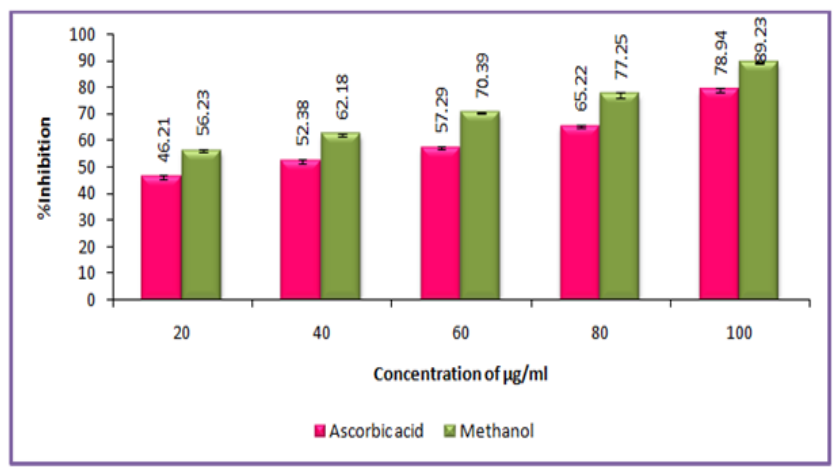

Figure 3 Antioxidant activity (2, 2-diphenyl-I-picrylhydrazyl assay) of methanol extract of Clausena excavata leaf.

\section{Antioxidant activity (NO2) of hexane, ethyl acetate and methanol extracts of Clausena excavata}

Antioxidant activity $\left(\mathrm{NO}_{2}\right)$ of different solvent extracts of Clausena excavata was tested and the data observed were depicted in the Figure 2. It was observed that the $\mathrm{NO}_{2}$ activity was found to be 14.25 and $72.39 . \%$ in the hexane extract of $C$. excavata. Similarly, the ethyl acetate extract of $C$. excavata leaf showed 19.33 and $82.17 \%$. Whereas, the maximum antioxidant activity $\left(\mathrm{NO}_{2}\right)$ was recorded in the methanol extract and values were found to be 28.37 and $91.25 \%$ in $20,40,60,80$ and $100 \mu \mathrm{g} / \mathrm{ml}$ concentrations respectively (Table 2) (Figure 5).

Table 2 Antioxidant activity (NO2scavenging assay), of different solvent extract of Clausena excavata leaf.

Values represent mean $\pm S$.D of five replications. NO2: Nitric oxide

\begin{tabular}{|c|c|c|c|}
\hline \multirow{3}{*}{$\begin{array}{l}\text { Concentrations } \\
\text { tested }\end{array}$} & \multicolumn{3}{|l|}{ Solvents used } \\
\hline & Hexane & Ethyl acetate & Methanol \\
\hline & \multicolumn{3}{|c|}{$\%$ of inhibition } \\
\hline 20 & $14.25 \pm 2.34$ & $19.33 \pm 1.17$ & $28.37 \pm 1.08$ \\
\hline 40 & $46.29 \pm 1.21$ & $55.29 \pm 3.67$ & $66.23 \pm 3.87$ \\
\hline 60 & $62.38 \pm 2.87$ & $71.26 \pm 2.47$ & $79.24 \pm 1.28$ \\
\hline 80 & $66.47 \pm 2.39$ & $76.21 \pm 3.54$ & $85.21 \pm 3.25$ \\
\hline 100 & $72.39 \pm 2.33$ & $82.17 \pm 1.28$ & $91.25 \pm 2.14$ \\
\hline
\end{tabular}

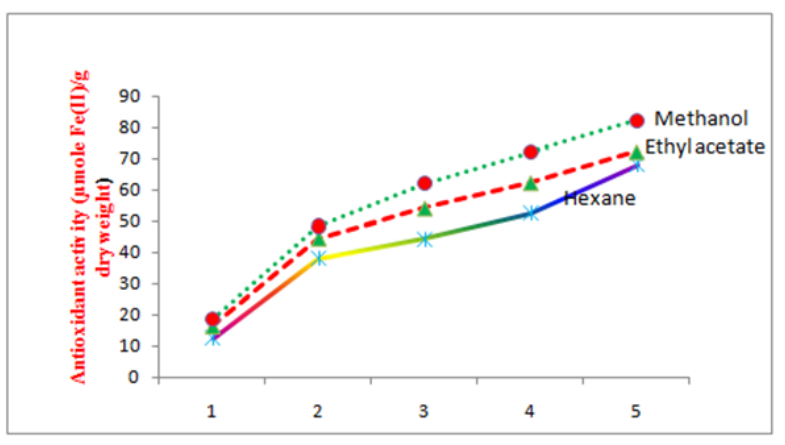

Figure 4 Antioxidant activity (FRAP assay) of different solvent extract of Clausena excavata leaf.

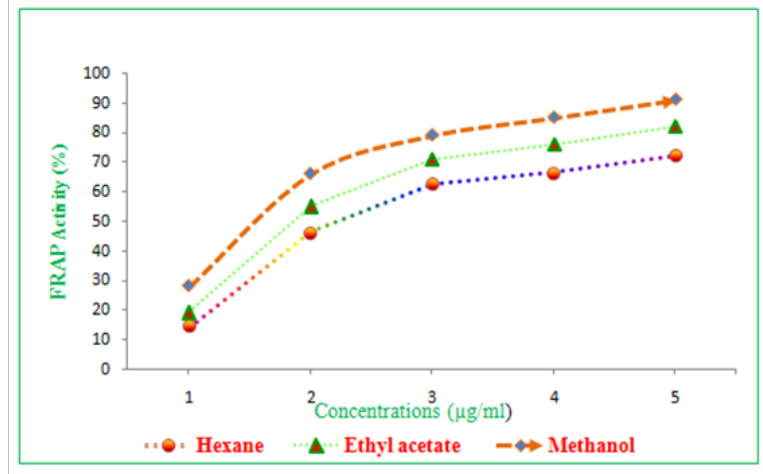

Figure 5 Antioxidant activity (NO2 scavenging assay), of different solvent extract of Clausena excavata leaf. 


\section{Phytochemical screening of hexane, ethyl acetate and methanol extracts of $\mathrm{C}$. excavata}

The phytochemical screening of selected plant extracts was assessed and the results pertaining to the experiments are shown in Table 3. The observations with regards to this, clearly indicated that the presence of coumarins alone in the ethyl acetate and methanol extract of C. excavata. Whereas, the presence of alkaloids, flavonoids, glycosides, phenolics, annins, saponins and coumarins in the ethyl acetate extract of the same plant. Similarly, the methanol extract showed the presence of alkaoilds, flavonoids, saponins, tannins, coumarins, Glycosides and phenolics (Table 1).

\section{Quantitative phytochemical screening of different extracts of $C$. excavate leaf}

The total phenolic content was estimated for the hexane, ethyl acetate and methanol extracts of C. excavata and Galic Acid was used as control and the values shown in Table 4. It was observed that $64.24 \pm 0.21 ; 71.16 \pm 0.25$ and $82.42 \pm 0.64 \mathrm{mg}$ galic acid equivalent $/ \mathrm{g}$ dry with were recorded against hexane, ethyl acetate and methanol extracts of $C$. excavata respectively. Similarly, the total flavonoids were recorded as $57.54 \pm 0.87,62.12 \pm 0.64$ and $71.28 \pm 0.38 \mathrm{mg}$ rutin equivalent/g dry with in hexane, ethyl acetate and methanol extracts of $C$. excavata respectively (Table 4).

Table 3 Qualitative analysis of phytochemicals in different solvent extracts of Clausena excavates.

(+)-Presence, (-)-Absence

\begin{tabular}{llll}
\hline Phytochemical screening & \multicolumn{4}{l}{ Extracts tested } \\
\hline & Hexane & Ethyl acetate & Methanol \\
\hline Alakaloids & + & + & + \\
Anthoquions & - & - & - \\
Carbohyrate & + & - & - \\
Cumarins & + & - & - \\
flavonoids & + & - & + \\
Glycosides & - & + & + \\
Phenols & + & + & + \\
Resins & - & + & - \\
Saponins & + & + & - \\
Steroids & + & - & \\
Tannins & + & + & + \\
Terpenoids & - & + & - \\
\hline
\end{tabular}

Table 4 Estimation of total phenolicsand flavonoids in different extracts of Clausena excavate

\begin{tabular}{lllll}
\hline \multirow{2}{*}{ Contents } & \multicolumn{2}{l}{ Extracts tested } & \multirow{2}{*}{ Control } \\
\cline { 2 - 4 } & Hexane & Ethyl acetate & Methanol & \\
\hline $\begin{array}{l}\text { Total } \\
\text { Phenolics* }\end{array}$ & $64.24 \pm 0.21$ & $71.16 \pm 0.25$ & $82.42 \pm 0.64$ & $89.00 \pm$ \\
Total & & & & 0.00 \\
Flovonaids** & $57.54 \pm 0.87$ & $62.12 \pm 0.64$ & $71.28 \pm 0.38$ & $\begin{array}{l}84.00 \pm \\
0.00\end{array}$ \\
\hline
\end{tabular}

*The total phenolic content was calculated from the calibration curve, and the results were expressed as $\mathrm{mg}$ of gallic acid equivalent per $\mathrm{g}$ dry weight.**The total flavonoids content was calculated from a calibration curve, and the result was expressed as $\mathrm{mg}$ rutin equivalent per $\mathrm{g} d r y$ weight.Values represent mean \pm SD of three replications.

\section{Discussion}

There is an inverse relationship between the nutritional intake of antioxidant rich food and the frequency of the human disease Rice Evans et al. ${ }^{20}$ The ethyl acetate and the methanol leaf extracts of Clausena excavate had shown the gradual increase in a dose dependent manner in the DPPH activity in terms of percentage inhibition depicted in (Figures 1-3). Antioxidant activity $\left(\mathrm{NO}_{2}\right.$ reducing assay) of different solvent extract of $C$. excavata leaf was assessed and the data pertaining to the experiment were shown that were recorded in the methanol extract of $C$. excavate was found significant $\% \mathrm{NO}_{2}$ reducing activity is directly proportional to the concentration of the extract and also the polarity of the solvents, because, increasing trend of $\mathrm{NO}_{2}$ reducing activity was noticed by the increase in the polarity of the organic solvents. In the present study, the phytochemical present in the solvent extracts also inhibited the free radicals in antioxidant activity method. The Terpenoids have been found to possess antioxidant and antimicrobial properties in various studies. ${ }^{21-23}$ The cardiac glycosides have been exhibited antioxidant and antimicrobial properties in various plant studies. ${ }^{24-30}$ Various plant extracts, showed the presence of steroids and these have been inhibited the many bacteria and found to possess antioxidant potentials. ${ }^{31-37}$ Presence of phenols in extract may explain its potent bioactivities as tannins are known to possess potent antioxidants and antibacterial activities. ${ }^{38-44}$ The present investigation has shown that methanol extract has active phytochemicals (terpenoids, flavonoids, coumarins and phenols) which are able to inhibit the pathogenic bacteria.

However, the presence of phenolic contents was traditionally speculated with the environmental stress experienced by the plant during the time of sampling. Evaluation of antioxidant properties of plants cannot be carried out accurately by a single universal method, Zengin et al. ${ }^{45}$ instead a set of assays could able to provide a clue about the activity. Total antioxidant capacity was reported as ascorbic acid equivalents and the method is mainly used for the spectrophotometric quantification of total antioxidant capacity that employs cost effective reagents Prieto et al. ${ }^{46}$ The strong antioxidant activity was confirmed in methanol extract. Both antimicrobial and antioxidant activity may be due to the strong occurrence of polyphenoloic compound such as terpenoids and phenols. These findings provide scientific evidence to support old-style uses and indicate a promising potential for the development and antimicrobial and antioxidant drug from C. excavate plant. ${ }^{47}$

\section{Conclusion}

The replacement of synthetic with natural antioxidants (because of implications for human health) may be advantageous. In the present study analysis of free radical scavenging activity, total phenolic and flavonoid content of C. excavata clearly showed that it can be used as a potent source of natural antioxidant.

\section{Acknowledgements}

None.

\section{Conflict of interest}

The author declares no conflict of interest. 


\section{References}

1. Bandyopadhyay U, Das D, Bannerjee RK. Reactive oxygen species: Oxygen damage and pathogenesis. Current Science. 1999;77(5):658-666.

2. Fang Y, Yang S, Wu G. Free radicals, antioxidants and nutrition. Nutrition. 2002;18(10):872-879.

3. Lee J, Koo N, Min DB. Reactive oxygen species, aging and antioxidative nutraceuticals. Comprehensive reviews in food science and food safety. 2004;3(1):21-33.

4. Cuzzocrea S, Riley DP, Caputi AP, et al. Antioxidant therapy: A new pharmacological approach in shock, inflammation and ischemia/ reperfusion injury. Pharmacol Rev. 2001;53(2):135-159.

5. Grice HC. Safety evaluation of butylated hydroxytoluene (BHT) in the liver, lung and gastrointestinal tract. Food Chem Toxicol. 1986;24:11271130 .

6. Tripathi, Land Tripathi NJ. Role of biotechnology in medicinal plants. Tropical Journal of Pharmaceutical Research. 2003;2(2):243-253.

7. Kaur C, Kapoor HC. Antioxidant activity and phenolic content of some Asian vegetables. International Journal of Food Science and Technology. 2002;37(2):153-161.

8. Aqil F, Ahmad I, Mehmood Z. Antioxidant and free radical scavenging properties of twelve traditionally used indian medicinal Plants. Turk J Biol. 2006;30:177-183

9. Manosroi A, Saraphanchotiwitthaya A, Manosroi J. Immunomodulatory activities of fractions from hot aqueous extract of wood from Clausenaexcavata. Fitoterap. 2004;75(3-4):302-308.

10. Rahman MT, Alimuzzaman M, ShilpiJ A, et al. Antinociceptive activity of Clausena excavata leaves. Fitoterapia. 2002;73(7-8):701-703.

11. Shukla S, Mehta A, John J, et al. Antioxidant activity and total phenolic content of ethanolic extract of Caesalpinia bonducella seeds. Food Chem Toxicol. 2009;47(8):1848-1851.

12. Guntupalli C, Kumar GS, Kumar AS, et al. Evaluation of antioxidan activity of the methanolic leaf extract of Clausena excavata Burm. $f$ (Rutaceae) using the lipid peroxidation model. Pharmacognosy Journal. 2012;4(34):22-25

13. Sunthitikawinsakul A, Kongkathip N, Kongkathip B. Coumarins and carbazoles from Clausena excavata exhibited antimycobacterial and antifungal activities. Planta Med. 2003;69(2):155-157.

14. Kumar R, Saha A, Saha D. A new antifungal coumarin from Clausena excavate. Fitoterap. 2012;83(1):230-233.

15. Arbab A, Abdul, AB, Aspollah M. A review of traditional uses, phytochemical and pharmacological aspects of selected members of Clausena genus (Rutaceae). Journal of Medicinal Plants Research. 2012;6(38):5107-5118.

16. Chang DS, Kuo YC, Chen TY. Productivity measurement of the manufacturing process for outsourcing decision: the case of a Taiwanese printed circuit board manufacturer. International Journal of Production Research. 2008:46(24):6981-6995.

17. Garrat CJ. The Signicance of insulin binding to tissue. Biochem J. 1964;90:17.

18. Markham KR. Techniques of Flavonoid Identification. London, UK Academic Press; 1982. p. 2-8.

19. HarborneJ B. Phytochemical methods. London, UK: Chapman and Hall Ltd. 1983. p. 49-188.
20. Rice Evans CA, Sampson J, Bramley PM, Why do we expect carotenoids to be antioxidants in vivo. Free Radic Res. 1997;26(4):381-398.

21. Liu XP, Luan JJ, Goldring CE. Comparison of the antioxidant activity amongst Gingko biloba extract and its main components. Zhong Yao Cai. 2009;32(5):736-740

22. Singh B, Singh S. Antimicrobial activity of terpenoids from Trichodesma amplexicaule Roth. Phytother Res. 2003;17(7):814-816.

23. Sauerwein M, Becker H. Growth, terpenoid production and antibacterial activity of an in vitro culture of the liverwort Fossombronia pusilla. Planta Med. 1990;56(4):364-367.

24. Maneemegalai S, Naveen T. Evaluation of antibacterial activity of flower extracts of Cassia auriculata. An International Journal of Ethnobotanical Research. 2010;2010(1)

25. Ajaiyeoba EO. Phytochemical and antibacterial properties of Parkia biglobosa and bicolor leaf Extracts. African Journal of Biomedical Research. 2002;5(3)

26. Patil SV, Salunke BK, Patil CD, et al. Potential of extracts of the tropical plant Balanites aegyptiaca (L.) Del. (Balanitaceae) to control mealybug,the Maconellicoccushirsutus (Homoptera: Pseudococcidae). Crop Protection. 2010;29(11):1293-1296.

27. Prasad NR, Viswanathan S, Renuka JD, et al. Preliminary phytochemical screening and antimicrobial activity of Samaneasaman. Journal of Medicinal Plants Research. 2008;2(10):268-270.

28. Ayoola GA, Coker HA, Adesegun SA, et al. Phytochemical screening and antioxidant activities of some selected medicinal plants used for malaria therapy in Southwestern Nigeria. Tropical Journal of Pharmaceutical Research. 2008;7(3):1019-1024.

29. Biapa PC, Agbor GA, Oben JE, et al. Phytochemical studies and antioxidant properties of four medicinal plants used in Cameroon. Afr $J$ Tradit Complement Altern Med. 2007;4(4):495-500.

30. Anyasor GN, Ogunwenmo KO, Oyelana OA, et al. Phytochemical constituents and antioxidant activities of aqueous and methanol stem extracts of Costus afer Ker Gawl. (Costaceae). African Journal of Biotechnology. 2010;9(31):4880-4884.

31. Savage PB, Li C, Taotafa U, et al. Antibacterial properties of cationic steroid antibiotics. FEMS Microbiol Lett. 2002;217(1):1-7.

32. Subhisha A, Subramoniam A. Antifungal activities of a steroid from Pallavicinialyellii. Indian J Pharmaco. 2005;37(5):304-308.

33. Taleb Contini SH, Salvador MJ, Watanabe E, et al. Antimicrobial activity of flavonoids and steroids isolated from two Chromolaena species. Brazilian Journal of Pharmaceutical Sciences. 2003;39(4):403-408.

34. Mann A, Yahaya Y, Banso A, et al. Phytochemical and antimicrobial activity of Terminalia avicennioides extracts against some bacteria pathogens associated with patients suffering from complicated respiratory tract diseases. Journal of Medicinal Plants Research. 2008;2(5):094-097.

35. Geethalakshmi R, Sarada DVL, Marimuthu P. Evaluation of antimicrobial and antioxidant potentials of Trianthema decandra L. Asian Journal of Biotechnology. 2010;2:225-231.

36. Phadungkit M, Rattarom R, Rattana S. Phytochemical screening, antioxidant, antibacterial and cytotoxic activities of Knema angustifolia extract. Journal of Medicinal Plants Research. 2010;4(13):1269-1272.

37. Shyamala GS, Vasantha K. Phytochemical screening and antibacterial activity of Syzygium cumini L. (Myrtaceae) leaves extracts. International Journal of PharmTech Research. 2010;2(2):1569-1573. 
38. Memnune S, Yildiz H, Gungor N, et al. Total phenolic content, antioxidant and antimicrobial activities of some medicinal plants. Pak J Pharm Sci. 2009;22(1):102-106.

39. Pereira JA, Oliveira I, Sousa A, et al. Walnut (Juglans regia L.) leaves: Phenolic compounds, antibacterial activity and antioxidant potential of different cultivars. Food Chem Toxicol. 2007;45(11):2287-2295.

40. Oliveira I, Sousa A, Ferreira IC, et al. Total phenols, antioxidant potential and antimicrobial activity of walnut (Juglansregia L.) green husks. Food Chem Toxicol. 208;46(7):2326-2331.

41. Gursoy N. Tepe B. Determination of the antimicrobial and antioxidative properties and total phenolics of two "endemic" Lamiaceae species from Turkey: Ballota rotundifolia L. and Teucrium chamaedrys C. Koch. Plant Foods and Hum Nutr. 2009;64(2):135-140.

42. Turkoglu S, TurkogluIKahyaoglu M Celik S. Determination of antimicrobial and antioxidant activities of Turkish endemic Ajuga chamaepitys L. Schreber subsp. Euphratica P.H. Davis (Lamiaceae). Journal of Medicinal Plants Research. 2010;4(3):1260-1268.
43. Roman M,Hradkova I, Filip V, et al. Antimicrobial and antioxidant properties of phenolic acids alkyl esters, Czech. J Food Sci. 2010;28(4):275-279.

44. Gulumser A, Dogan NM, Duru ME, et al. Phenolic profiles, antimicrobial and antioxidant activity of the various extracts of Crocus species in Anatolia. African Journal Microbiology Research. 2010;4(11):1154-1161.

45. Zengin G, Abdurrahman A, Guler GO, et al. Antioxidant Properties of methanolic extract and fatty acid composition of Centaureaurvillei DC.subsp. Hayekiana Wagenitz. Rec Nat Prod. 2011;5(2):123-132.

46. Prieto P, Pineda M, Aguilar M. Spectrophotometric quantitation of antioxidant capacity through the formation of a phosphor molybdenum complex:specific application to the determination of vitamin E. Anal Biochem. 1999;269(2):337-341.

47. Ayoola GA, Coker HA, Adesegun SA, et al. Phytochemical screening and antioxidant activities of some selected medicinal plants used for malaria therapy in Southwestern Nigeria. Tropical Journal of Pharmaceutical Research. 2008;7(3):1019-1024. 